vice and have welcomed its increase. They realize the economic value of such service and acknowledge that they have a responsibility in management beyond that of being merely custodians of the shareholders' money. This outlook is encouraging and provides greater reason for confidence that the service must have a place of no little importance in any future health planning for the nation. On the other hand there are still employers of labour who consider that the health of their employees is little or none of their business ; they are prepared to fulfil the letter of the law and keep their statutory obligations, but are unwilling to go further. Where doctors are appointed under the new Order to such firms they have a great responsibility. They have to prove to the employer that the service they are giving is helpful not only to the workers but to industry as a whole, and one not lightly to be discarded after the war.

BIBLIOGRAPHY

Bashford, H. H. (1938), Proc, roy. Soc. Med., 31, 185

Birmingham Accident Hospital : Memorandum on its Policy Relating to Industry (1941).

Collis, E. L., and Greenwood, M. (1921). The Health of the Industrial Worker, London.

Factories Act (1937). H.M. Stationery Office, London.

First Aid in Industry (1939). British Medical Association, London.

Health of Munition Workers Committee (1915-17) : Reports and Memoranda. H.M. Stationery Office, London.

H.M. Chief Inspector of Factories, Annual Reports. H.M. Stationery Office, London.

Home Office Welfare Pamphlets, Nos. 1-8. H.M. Stationery Office, London. Industrial Health Research Board, Annual Reports. H.M. Stationery Office, London.

Industrial Health in War (1939) : Emergency Report No. 1. Industrial Health Research Board. H.M. Stationery Office, London.

Ling, T. M. (1937). Recent Advances in Industrial Hygiene and Medicine, London. Lockhart, L. P. (1935). Med. Ann., 266, Bristol.

Memorandum on Medical Supervision in Factories (1940). H.M. Stationery Office, London.

P E P (1937). Report on British Health Services, P E P, London.

Stewart, D. (1939). Milroy Lectures. British Medical Journal, 1, 963, 1019.

Vernon, H. M. (1940). Health and Efficiency of Munition Workers, Oxford University Press.

\section{"ETHER CONVULSIONS"}

\section{BY}

\section{H. J. BRENNAN, M.D., D.A.}

Anaesthetist, Manchester Royal Infirmary; Temporary Major, R.A.M.C.

"Ether convulsions" were described simultaneously in May, 1927, by two Manchester anaesthetists-K. B. Pinson (1927) and the late S. R. Wilson (1927). Pinson thought them to be due to an over-accumulation of $\mathrm{CO}_{2}$. This explanation has never been generally accepted, for not only have convulsions occurred during endotracheal administrations, when the alveolar $\mathrm{CO}_{2}$ content is at its lowest, but the administration of $\mathrm{CO}_{2}$ has been found an effective method of -treatment. Wilson, on the other hand, attributed the convulsions to impurities in the ether, aldehydes and peroxides having been detected in the samples used. Walton (1928) found impurities which supported Wilson's theory, but Sykes (1930) and Ross Mackenzie (1931) did not find them, or only in such minute quantities as to be negligible. This theory, however, received much attention both from the chemical houses producing ether and from the makers of anaesthetic apparatus. It became customary to sell ether in dark-coloured bottles wrapped in black paper, and the ether bottles of some anaesthetic apparatus were made of heavily tinted glass. Later, copper was found to be a powerful anticatalytic agent, and the tubes which dip into the ether in Boyle's and similar machines were subsequently made of this metal. In spite of these precautions convulsions still occurred, and it has long been generally accepted that impure ether could not be regarded as their cause. Conclusive evidence of the correctness of this view is the fact that typical "ether convulsions." have occurred when no ether has been used-for example, during operations under local (Hudson, 1936), chloroform (Bull, 1927), and nitrous-oxide-oxygen anaesthesia (Sington, 1927).

'When the convulsions were first described it 'was uncharitably suggested that these new and extraordinary phenomena might be due to faulty provincial technique. As reports were published of similar convulsions having been seen in all parts of the country this explanation had quickly to be abandoned, but, as will appear later in this paper, I consider the frequency with which they have occurred in Manchester to have a definite aetiological significance.

Since Pinson and Wilson first described this condition much has been written on the subject. Many case reports have appeared and numerous theories have been advanced, though none of them has been universally accepted. This is possibly because no one theory has explained and fitted in with all the known facts and the many observations that have been made. It is common knowledge, however, that the combination of youth, heat, and a septic condition with pyrexia occurs in some $85 \%$ of cases, and on this account the heat-stroke theory, first put forward by Dickson Wright (1935) and upheld by Woolmer and Taylor (1936), has received more support than any other. It is proposed in the present paper to support and elaborate both this theory and that of neurogenic shock advanced by Hudson (1936) and to explain the occurrence of the hyperpyrexia.

I suggest that ether convulsions are caused by a strong neurogenic stimulus in a hyperpyrexial patient. I consider that the hyperpyrexia is due to the administration of a general anaesthetic to a dehydrated pyrexial subject in a hot humid atmosphere, the subsequent rise in temperature possibly being increased by the previous administration of atropine.

\section{Neurogenic Stimuli}

In the cases recorded in Hudson's valuable paper the convulsions were undoubtedly initiated by neurogenic stimuli. This is equally true of a case reported verbally to the Anaesthetic Section of the Royal Society of Medicine. The last-mentioned patient was being given nitrousoxide - oxygen for a thyroidectomy and had been premedicated with omnopon-scopolamine. The surgeon pulled rather hard to expose the upper pole, and convulsions started immediately. These settled in a minute or two, the operation was continued, and the surgeon repeated his over-forceful manœuvre, whereupon the convulsions immediately restarted.

The exact stage of the operation at which convulsions began has unfortunately not been mentioned in all the published case reports. In the majority of those in which it has been recorded one cannot but be struck by such oft-recurring phrases as " just as the peritoneum was being opened" or "while the peritoneum was being shut"-i.e., while the peritoneum was being lifted upwards, possibly rather forcibly. Again, in two or three cases bone chiselling was taking place at the moment of onset. I have seen one case in which convulsions started the moment the peritoneum was picked up by forceps previous to incision. The convulsions were controlled and the operation continued. The convulsions restarted when the peritoneum was picked up again as a preliminary to closure. I have seen another case in which the convulsions definitely started just as cross-action peritoneal forceps were applied. Yet another case of mine showed this initiating nociceptor factor even more dramatically.

The patient, a boy aged 8 , was suffering from an acute mediastinitis due to a swallowed pin, which had passed through the oesophagus. He was extremely ill, was badly dehydrated, 
and had a temperature of $103.8^{\circ} \mathrm{F}$. I gave him nitrous oxide, oxygen, and ether from a Boyle machine via a Magill tube. The posterior mediastinum was opened under very light anaesthesia. The surgeon saw the pin at the bottom of the wound and turned round to choose a suitable instrument with which to extract it. Meanwhile his assistant unfortunately inserted and pulled on a deep retractor. The boy's pulse immediately halved its rate, and within a few seconds he experienced typical violent generalized convulsions.

It must be emphasized that it is not considered that neurogenic stimuli alone will cause convulsions. Every year thousands of patients receive gross peritoneal and other nervous insults without showing any alarming symptoms. But in the presence of hyperpyrexia, whether or not a general anaesthetic has been given, severe neurogenic stimuli are apt to initiate convulsive symptoms, though admittedly the latter very occasionally may occur without the patient having received any sensory stimuli-e.g., before the start of the operation.

The-nature of the underlying biochemical change associated with the hyperpyrexia and predisposing to convulsions is not at present understood, though in this connexion the alteration of the wave-and-spike electrical activity of petit mal resulting from changes in blood-sugar concentrations (Gibbs, Gibbs, and Lennox, 1939) is of interest and worthy of further study.

\section{Hyperpyrexia}

There is a considerable volume of evidence in the literature that hyperpyrexia is present in patients who have had ether convulsions. I can add to this record two cases in which $\mathrm{I}$ found rectal temperatures of $108^{\circ}$ and $108.5^{\circ} \mathrm{F}$. immediately after short convulsions.

The possible factors leading to this hyperpyrexia must be carefully considered. In a typical case of ether convulsions the patient is 5 to 15 years of age and is suffering from an acute septic condition-often an acute appendicitis of forty-eight hours' standing. He has a raised body temperature and the weather is hot. All these factors, with the common addition of vomiting and reduction in fluid intake, combine to cause a severe degree of dehydration.

It was considered in the past that simultaneously with a rise in the skin temperature of the extremities (Scott and Morton, 1931) a fall in body temperature occurred under ether anaesthesia. Watkins and Wilson (1927) showed, however, that this was true only of quiescent-interval cases, and that in acute cases in dehydrated subjects body temperature rose during ether anaesthesia. I have repeated, and confirmed, the latter observation on a series of patients.

I have found that a dehydrated subject with a temperature of, say, $101^{\circ} \mathrm{F}$. who is given a general anaesthetic is, particularly if young, likely, under the best conditions as regards theatre ventilation, to return to the ward with a temperature about $2^{\circ}$ higher. If theatre conditions are not optimal his temperature may rise considerably more. The association between hot weather and ether convulsions has often been noted. As has been mentioned, hot weather can exert an influence by increasing the patient's pre-operative dehydration. It can also raise the temperature of oldfashioned theatres. The temperature of the theatre is not, however, of very great importance per se. It is the wetbulb temperature and the relative humidity which matter. Hamilton Bailey (1940) recently cast doubt upon the heatstroke theory when reporting two cases which occurred in extremely cold weather. Without a record of the wet-bulb temperatures of the theatres this observation does not carry much weight.

On two occasions I have been able to measure the wetbulb temperatures of theatres immediately after ether con- vulsions had occurred, and found readings of $78^{\circ}$ and $79^{\circ} \mathrm{F}$., the latter being only $1^{\circ} \mathrm{F}$. less than the temperature at which, under Board of Trade regulations, cotton factories must be evacuated. Every degree rise in wet-bulb temperature reduces the amount of heat which the body can lose. It follows that if a dehydrated pyrexial young subject is anaesthetized in a hot humid theatre the expected rise in temperature of $2^{\circ}$ to $3^{\circ} \mathrm{F}$. may be greatly exceeded. I would suggest that this is the reason why Manchester has seen such a regrettable number of ether convulsions, the prevailing humidity being notorious.

In this connexion it is interesting to note that no case of ether convulsions has occurred in any of five busy airconditioned theatres in that city since they were built six years ago.

\section{Atropine}

Hornabrook (1927) first suggested that large doses of atropine were the chief cause of ether convulsions. Sington (1927) rather refuted this idea on the evidence of the Hospital for Sick Children, Great Ormond Street, where 7,000 children are operated on each year and where all receive large doses of atropine. While there is no evidence that atropine ever acts directly as a convulsive agent in these cases, as Hornabrook suggested, but rather the reverse, it is possible that it does contribute to the hyperpyrexia.

Observations were made on the effect of atropine on the rise of body temperature which occurs in a hot atmosphere with a high-percentage saturation of moisture. Three subjects sat for twenty minutes in a room of a Russian bath. When they had cooled down again each was given 1/60 grain of atropine subcutaneously. Half an hour later they sat for another twenty minutes in the Russian bath. Their temperatures on the different occasions are given below :

\begin{tabular}{|c|c|c|c|c|}
\hline - & & I & II & III \\
\hline $\begin{array}{l}\text { Before experiment } \\
\text { After } 20 \text { minutes in Russian bath } \\
\text { Return to normal } \\
\text { After } 20 \text { minutes in Russian bath } \\
\text { after injection of atropine }\end{array}$ & $\begin{array}{l}\cdots \\
\cdots \\
1 / 2 \text { hour } \\
\cdots\end{array}$ & $\begin{array}{r}97^{\circ} \\
100^{\circ} \\
97^{\circ}\end{array}$ & $\begin{array}{r}97.4^{\circ} \\
100.4^{\circ} \\
97.6^{\circ}\end{array}$ & $\begin{array}{c}98^{\circ} \\
100 \cdot 2^{\circ} \\
98^{\circ}\end{array}$ \\
\hline
\end{tabular}

These results showed that the very hot humid atmosphere caused a slightly greater rise in body temperature after the administration of atropine. Incidentally the atropine also caused a very marked and unpleasant exaggeration of the subjective symptoms.

\section{Treatment}

Acceptance of these theories opens up a definite line of treatment which must primarily be preventive. This dangerous complication can be very largely averted, and particular care should be taken to remove the exciting factors in those subjects in whom the onset of the condition might be feared.

1. The dehydrated pyrexial young patient should be put on a glucose-saline drip before operation, and anaesthesia should not be induced until at least 1 to 2 pints have been given.

2. All new theatres should, of course, be air-conditioned. Apart from this, much may be done to improve existing theatres by the use of extractor fans, air vents, steam condensers, removal of sterilizers outside theatres, and similar steps. A wet-and-dry-bulb thermometer should be found in every general theatre, and an anaesthetist should normally refuse to induce a dehydrated young patient if the wet-bulb temperature is over $70^{\circ} \mathrm{F}$.

3. It is unnecessary to emphasize here the importance of gentle surgery and of avoiding neurogenic trauma. So far as the anaesthetist is concerned, he should see that the depth of anaesthesia is always adequate for the stage of the operation in progress.

4. Heavy mackintosh coverings should not be used. 
5. The patient should be intubated immediately if the anaesthetist feels that convulsive symptoms are at all imminent.

I do not consider that atropine should be withheld, providing the other and more important points have received attention.

Active treatment should be as follows if a convulsion occurs despite precautions:

1. If an inhalational anaesthetic is being given it should be discontinued immediately and $\mathrm{O}_{2}$ and $\mathrm{CO}_{2}$ administered.

2. All coverings should be removed from the patient. The limbs should be sprayed with cold water (a stirrup pump is excellent for this purpose) and evaporation hastened by air currents from viaved towels, oxygen cylinders, etc.

3. The table should be placed in a slight reverse Trendelenburg position.

4. If, as often happens, convulsions cease temporarily in a minute or so, the patient should be intubated if this has not already been done.

5. If convulsions have not ceased in tiris time a small intravenous dose of a barbiturate should be given.' In practice this means that a nurse or student should prepare some pentothal or evipan on the first sign of a convulsion and that it should be given as soon as it is ready if the convulsions are still in evidence.

6. If the patient has not been intubated this must be done immediately the barbiturate has controlled the convulsions sufficiently to make it possible, and rhythmic insufflation with oxygen must be performed. This is most important. Barbiturates can and will save lives in ether convulsions, but they can also cause fatal respiratory paralysis. A case of ether convulsions which ends fatally usually does so with a cyanosed patient and a tonically contracted larynx. A barbiturate given shortly before this stage is reached-and it may occur within as little as a minute or two of the first symptom-may check the convulsion, but there is a danger that respiratory movements may never begin again unless pulmonary ventilation is artificially performed from the earliest possible moment.

7. If the stage of the operation demands further anaesthesia with relaxation, ether may be restarted or continuous barbiturate anaesthesia may be substituted. The ether is only one of the several contributing factors which go to initiate a convulsion, and, especially in unskilled hands, a change over to chloroform may well do more harm than good.

\section{Differential Diagnosis of Ether Convulsions}

Many writers have emphasized the difference between convulsions and ether clonus, a harmless though annoying complication which appears early and usually disappears as anaesthesia deepens. There is, however, another type of movement which I have seen on a number of occasions, but which is not mentioned in the literature-namely, regular rhythmical movements of one or more muscle groups, usually occurring early in the third stage and soon passing away, but occasionally persisting into deep anaesthesia. I have seen these movements affecting a single finger, a hand, a foot, a knee, and on one occasion the head. . Movement occurs in relation to respiration, usually every third or fourth breath. None of the patients showing these movements was at all inconvenienced by them or was the least source of anxiety to me. No treatment was necessary. I mention them because on two occasions I have known house-surgeons see these movements affecting the eyebrows and mistake them for the irregular premonitory twitchings which so often herald convulsions.

\section{Summary and Conclusions}

It is suggested that ether convulsions are caused by neurogenic stimuli in hyperpyrexial patients.

It is shown that hyperpyrexia will result from the administration of general anaesthesia to a dehydrated patient in a hot humid atmosphere.

Logical methods of preventive and active treatment are described.

\section{REFERENCES}

Bailey, Hamilton (1940). British Medical Journal, 2, 222.

Bull, L. J. F. (1927). Ibid., 2, 471.

Gibbs, F. A., Gibbs, E. L., and Lennox, W. G. (1939). Arch. Neurol. Psychiat. Chicago, 41, 1111 .

Hornabrook, R. W. (1927). British Medical Journal, 2, 471.

Hudson, R. V. (1936). Brit. J. Anaesth., 13, 148.

Mackenzie, J. Ross (1931). British Medical Journal, 1, 440.

Pinson, K. B. (1927). Ibid., 1, 956.

Scott, W. J. M., and Morton, J. J. (1931). Arch. intern. Med., 48, 1065.

Sington, H. (1927). British Medical Journal, 2, 567.

Sykes, W. S. (1930). Ibid., 1, 1128.

Walton, A. C. R. (1928). Ibid., 2, 8.

Watkins, K. H , and Wilson, S. R. (1927). Brit. J. Anaesth., 4, 201.

Wilson, S. R. (1927). Lancet, 1, 1117

Woolmer, R. F., and Taylor, S.'(1936). Ibid., 1, 1005

Wright, A. Dickson (1935). British Medical Journal, 1, 949.

\section{ENCOPRESIS (INCONTINENCE OF FAECES) IN CHILDREN}

BY

CHARLES BURNS, M.R.C.S., L.R.C.P., D.P.M.

Director, Child Guidance Clinic, Birmingham; Psychologist, Midland Nerve Hospital; Psychiatrist, E.M.S.

The term “encopresis" was suggested by Weissenberg (1926) for those cases of faecal incontinence in which no definite organic lesion is found. As a shortened description, and the counterpart of " enuresis," it is perhaps worthy of adoption. The condition has not had the attention it deserves compared, for example, with enuresis, and receives scant mention in textbooks of paediatrics.

Although encopresis is much less common thàn enuresis, it is certainly more distressing, and is often, too, a symptom of severe neurosis. The fact that the child will "grow out of it" is no reason for not hastening the process of cure, particularly at the present time, when the condition is fairly prominent among problems of evacuation. The complaint cannot be classified simply under one heading, for it varies from mere soiling, diurnal or nocturnal, to those cases in which there is not only incontinence but also playing with faeces-decorating the bed or the wall, or depositing the scybala in out-of-the-way places. An attempt is here made to describe some of the cases observed at a child guidance clinic and followed up long enough to see the outcome of treatment or of the lapse of time.

Cases of incontinence of faeces may be divided into (1) simple soiling, (2) neurotic cases, and (3) cases associated with petit mal or vasovagal conditions. Partial soiling of bed or trousers must be distinguished from the passage of formed scybala either involuntarily or semi-voluntarily. The former may be due to sheer hastiness, carelessness, or lack of training. Again, it may be due to fear of asking to leave the room, fear of a dark lavatory or passage, or simple lack of enough leisure in a badly managed home. There is, of course, no sharp dividing line between these cases and those in which there is an element of neurosis.

\section{Reports of Cases}

The following case illustrates treatment by child guidance methods, chiefly play therapy, and also the environmental factors involved.

A girl aged $12 \frac{1}{2}$ was referred to the child guidance clinic from hospital, where she had been an in-patient under observation. The incontinence had started about three years previously and had occurred by day and by night. No physical abnormality was found. She was also stated to have tempers and to walk in her sleep. She was the eldest of three girls, and had shown intense jealousy of both her sisters. The father was given to drink, and has twice left home owing to rows with his motherin-law.

The patient was a normal baby, though difficult to train. At the age of 6 she sustained slight concussion, and when 8 was 